\title{
Influence of the Neutron Flux Characteristic Parameters in the Irradiation Channels of Reactor on NAA Results Using $\boldsymbol{k}_{0}$-Standardization Method
}

\author{
Tran Van Hung \\ Research and Development Center for Radiation Technology, \\ Hochiminh City, Vietnam \\ Email: tranhungkeiko@yahoo.com
}

Received November 28, 2011; revised January 5, 2012; accepted January 16, 2012

\begin{abstract}
An approximation method using to estimate the influence of the uncertainties of the neutron flux characteristic parameters in the irradiation positions on the NAA results using $k_{0}$-standardization technique was presented. Those are the epithermal reactor neutron spectrum shape-factor $\alpha$, the effective resonance energy $\bar{E}_{r}$ for a given nuclide and the thermal to epithermal neutron flux ratio $f$. The method is applied to estimate the effect of the uncertainties in the determination of $\alpha, \bar{E}_{r}$ and $f$ on final NAA results for some irradiation channels of the Dalat reactor. It also shows that presented method is suitable in practical use for the estimation of the errors due to the uncertainty of the neutron flux characteristic parameters at the irradiation position.
\end{abstract}

Keywords: $k_{0}$-Standardization Technique; Error Propagation Function; Neutron Flux Characteristics; Dalat Reactor

\section{Introduction}

Since the $k_{0}$-standardization method was introduced in NAA [1], it has been broadly applied in the reactor in the world. The fundamental concept of $k_{0}$-method was being elaborated previously in great detail [1-3]. The concentration of an element in the $k_{0}$-method is calculated by:

$$
\rho(p p m)=\frac{\frac{N_{p} / t_{m}}{S D C W}}{\left(\frac{N_{p} / t_{m}}{S D C w}\right)^{*}} \frac{1}{k_{0}} \frac{f+Q_{0}^{*}(\alpha)}{f+Q_{0}(\alpha)} \frac{\varepsilon_{p}^{*}}{\varepsilon_{p}}
$$

with $k_{0}$ in Equation (1) defined as:

$$
k_{0}=\frac{M^{*} \theta \sigma_{0} \gamma}{M \theta^{*} \sigma_{0}^{*} \gamma^{*}}
$$

In Equations (1) and (2):

$M$-atomic mass;

$\theta$-isotopic abundance;

$\sigma_{0}-2200 \mathrm{~m} \cdot \mathrm{s}^{-1}(n, \gamma)$ cross-section;

$\gamma$-absolute gamma-intensity;

$N_{p}$ - peak area corrected for pulse losses;

$W$-sample weight in gram;

$w^{*}$ - comparator weight in microgram;

$S=1-\exp \left(-\lambda t_{i r r}\right) ; t_{i r r}$-irradiation time; $\lambda$-decay constant;
$D=\exp \left(-\lambda t_{d}\right) ; t_{d}-$ decay time;

$C=\left[1-\exp \left(-\lambda t_{m}\right)\right] / \lambda t_{m} ; t_{m}$-measuring time;

$f$ - thermal to epithermal neutron flux ratio;

$Q_{0}(\alpha)=I_{0}(\alpha) / \sigma_{0} ; I_{0}(\alpha)$-resonance integral corrected for a non-ideal epithermal neutron flux distribution (assumed $\left.1 / E^{1+\alpha}\right)$;

$\varepsilon_{p}$-detector's efficiency;

When the epithermal neutron flux distribution deviates from ideality, i.e. it does not follow the $1 / E$-law, $Q_{0}(\alpha)$ of nuclide $i$ can be written by:

$$
\begin{aligned}
Q_{0 i}(\alpha)= & \left(Q_{0 i}-0.429\right) /\left(\bar{E}_{r i}\right)^{\alpha} \\
& +0.429 /\left[(2 \alpha+1)(0.55)^{\alpha}\right]
\end{aligned}
$$

with $\alpha$-neutron spectrum shape factor deviating from the $1 / E$-law, independent of neutron energy and $|\alpha| \ll 1$.

$\bar{E}_{r i}$-effective resonance energy of nuclide $i$.

The asterisks in Equations (1) and (2) refers to the comparator, which is suitable for coirradiation with the sample; in most case, $\mathrm{Au}$ is used as a comparator. The $k_{0}$-factors to $\mathrm{Au}$ for interested isotopes in NAA were experimentally determined and tabulated in report [4] with an accuracy which better than $2 \%$ (average $\sim 1 \%$ ). The relevant nuclear data as $Q_{0 i}$ and $\bar{E}_{r i}$ can be found in a tabulated form or in a computer library. $\alpha, f$ and $\varepsilon_{p}$ must be experimemently determined and they depend on spe- 
cific irradiation channel and detector, which are used in practice. The detector's efficiency $\left(\varepsilon_{p}\right)$ can be determined with an uncertainty about $2 \%$; but the uncertainty of $\alpha$ can be more than $10 \%$, even bigger, depend on the irradiation channels in reactor. Since the term $\left[f+Q_{0}^{*}(\alpha)\right] /$ $\left[f+Q_{0}(\alpha)\right]$ in Equation (1), it is clear that an additional parameter, $\bar{E}_{r i}$, should be considered, because the uncetainties of $\bar{E}_{r i}$ of some nuclides are about $20 \%$ $[4,5]$.

The accuracy and the applicability of the $k_{0}$-standardization method were detailly presented in paper [5] by F. De CORTE et al. In paper [6], J. OP De BEEK evaluated the effect of errors of $\alpha$ and $\bar{E}_{r i}$ on the results in terms of concentration, based on the ${ }^{197} \mathrm{Au}$ comparator; in that $Q_{0 i}(\alpha)$ was approximated by :

$$
Q_{0 i}(\alpha) \approx Q_{0 i}\left(\bar{E}_{r i}\right)^{-\alpha}
$$

However, with this approximation, it led that some results in paper [6] have to be put to discussion (see below).

In this work, we carry out an approximation method to evaluate the effect of errors of $\alpha$ and $\bar{E}_{r i}$ on the NAA results in the $k_{0}$-standardization method. The obtained results showed that the approximate method in this work is acceptable with confident accuracy.

\section{Base of Approximation}

As we know, $\alpha$ value is smaller than unity in absolutte value. In practice, in irradiation channels of reactor, absolute value of $\alpha$ is less than 0.2 (in most cases, $|\alpha|<$ 0.1 and this condition is satisfactory in reactor core). In the approximation of J. OP De BEEK, it is good for the nuclides having $Q_{0 i}>1$, but is not for the nuclides with $Q_{0 i}<1$. Due to $|\alpha| \ll 1$, in paper [7,8], we suggest substituting $Q_{0, i}(\alpha)$ from Equation (3) by the following approximated formula:

$$
\begin{gathered}
Q_{0 i}(\alpha) \approx Q_{0 i}\left(\bar{E}_{r i}\right)_{i}^{-a \alpha} \\
\text { or } Q_{0 i}(\alpha) \approx Q_{0 i} \exp \left(-a_{i}\left(\ln \bar{E}_{r i}\right) \alpha\right)
\end{gathered}
$$

where $a_{i}$ is constant for each nuclide and determined by fitting the values of $Q_{0 i}(\alpha)$, which are calculated from Equation (3) in range $|\alpha| \leq 0.2$, then fitting according to function (5) (see reference [7,8]). Note that, $a_{i}$ of each nuclide depends on the sign of $\alpha$. The values of $a_{i}$ for the interested nuclides in NAA are given in Table 1. Seeing the Equation (5), it differs to Equation (4) of J. OP De BEEK by a correctional coefficient $a_{i}$. However, it can be used good for all nuclides with uncertainties of the calculated $Q_{0, i}(\alpha)$ less than about $5 \%$ for the nuclides having $Q_{0 i}<1$ and less than about $2 \%$ for $Q_{0 i}>1$ with $|\alpha| \leq 0.2$. Indeed, we carried out a survey of the ratios of $Q_{0 i}(\alpha)$ calculated from Equation (5) (in this work) and Equation (4) (of J. OP De BEEK) to Equation (3) (accurate expression) for $Q_{0 \mathrm{i}}$ from $0.44\left({ }^{46} \mathrm{Sc}\right)$ to $248\left({ }^{97} \mathrm{Zr}\right)$ with $\alpha=-0.1$. The results are presented in Figure 1 and some results are presented in Table 2. Clearly, the approximated expression in this work is better than one of $\mathrm{J}$. OP De BEEK. Moreover, the calculated $Q_{0 i}(\alpha)$ from three expression Equation (3), Equation (4) and Equation (5) for ${ }^{45} \operatorname{Sc}(n, \gamma){ }^{46} \mathrm{Sc}$ presented in Table 3. The another nuclides presented in papers $[7,8]$ also confirm the above conclusion.

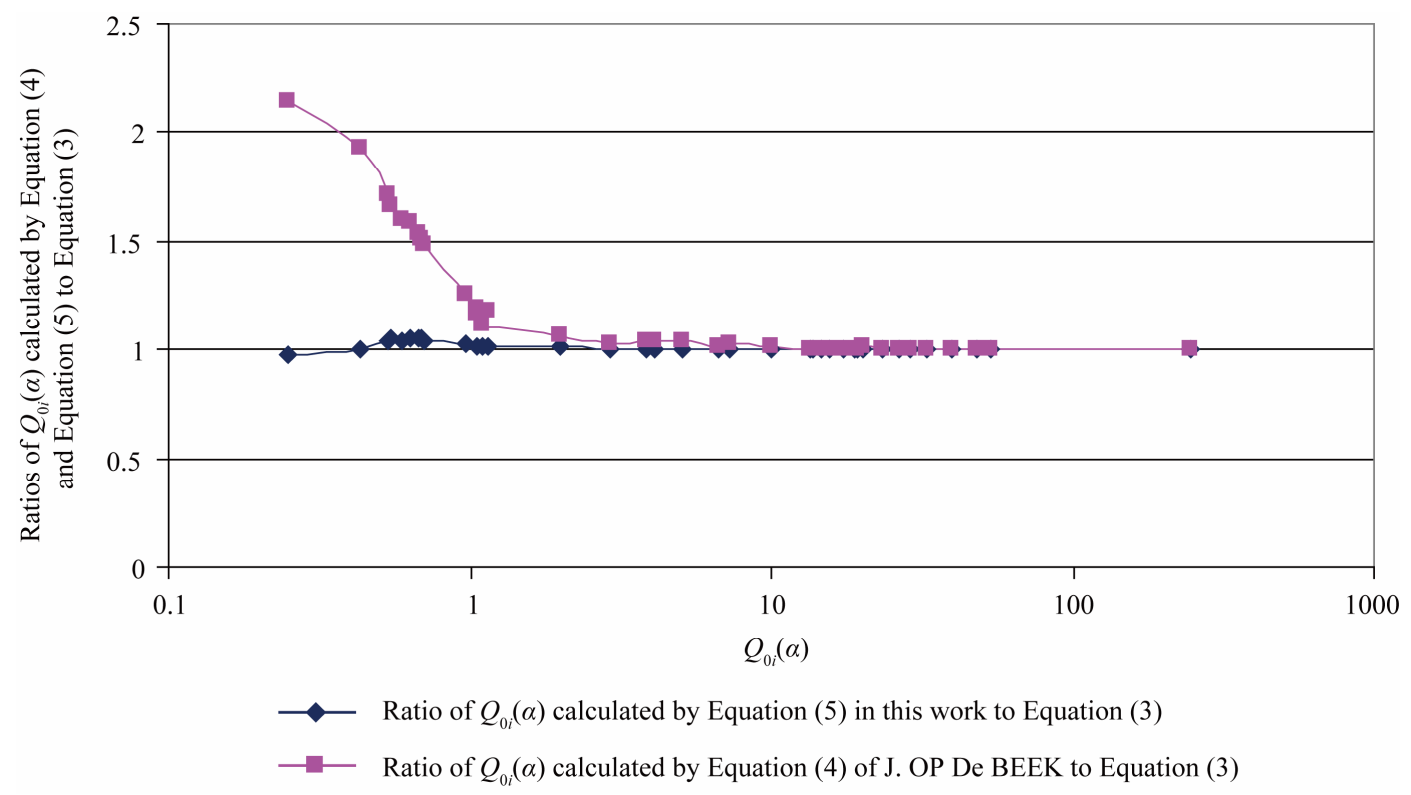

Figure 1. Survey of the ratios of $Q_{0 i}(\alpha)$ calculated from Equation (5) (in this work) and Equation (4) (of J. OP De BEEK) to Equation (3) (accurate expression) for different $Q_{0 i}$ with $\alpha=-0.1$. 
Table 1. The values of $a_{i}$ for the interesting nuclides in NAA.

\begin{tabular}{|c|c|c|c|c|c|c|c|}
\hline Target nuclide & Formed nuclide & $a_{i}$ with $\alpha<0$ & $a_{i}$ with $\alpha>0$ & Target nuclide & Formed nuclide & $a_{i}$ with $\alpha<0$ & $a_{i}$ with $\alpha>0$ \\
\hline${ }^{23} \mathrm{Na}$ & ${ }^{24} \mathrm{Na}$ & 0.524987 & 0.301907 & ${ }^{116} \mathrm{Sn}$ & ${ }^{117 \mathrm{~m}} \mathrm{Sn}$ & 0.996203 & 0.992120 \\
\hline${ }^{26} \mathrm{Mg}$ & ${ }^{27} \mathrm{Mg}$ & 0.600414 & 0.260458 & ${ }^{122} \mathrm{Sn}$ & ${ }^{123 \mathrm{~m}} \mathrm{Sn}$ & 0.958568 & 0.907080 \\
\hline${ }^{27} \mathrm{Al}$ & ${ }^{28} \mathrm{Al}$ & 0.632092 & 0.355905 & ${ }^{124} \mathrm{Sn}$ & ${ }^{125 \mathrm{~m}} \mathrm{Sn}$ & 0.996581 & 0.993233 \\
\hline${ }^{37} \mathrm{Cl}$ & ${ }^{38} \mathrm{Cl}$ & 0.618735 & 0.340898 & ${ }^{121} \mathrm{Sb}$ & ${ }^{122 \mathrm{~m}} \mathrm{Sb}$ & 0.99639 & 0.991949 \\
\hline${ }^{41} \mathrm{~K}$ & ${ }^{42} \mathrm{~K}$ & 0.744902 & 0.510677 & ${ }^{123} \mathrm{Sb}$ & ${ }^{124 \mathrm{~m}} \mathrm{Sb}$ & 0.993951 & 0.988375 \\
\hline${ }^{45} \mathrm{Sc}$ & ${ }^{46} \mathrm{Sc}$ & 0.225177 & 0.13871 & ${ }^{127} \mathrm{I}$ & ${ }^{128} \mathrm{I}$ & 0.991934 & 0.984365 \\
\hline${ }^{50} \mathrm{Ti}$ & ${ }^{51} \mathrm{Ti}$ & 0.61391 & 0.300434 & ${ }^{133} \mathrm{Cs}$ & ${ }^{134 \mathrm{~m}} \mathrm{Cs}$ & 0.993476 & 0.980868 \\
\hline${ }^{51} \mathrm{~V}$ & ${ }^{52} \mathrm{~V}$ & 0.484063 & 0.253348 & ${ }^{130} \mathrm{Ba}$ & ${ }^{131 \mathrm{~m}} \mathrm{Ba}$ & 0.991752 & 0.983823 \\
\hline${ }^{50} \mathrm{Cr}$ & ${ }^{51} \mathrm{Cr}$ & 0.444713 & 0.235221 & ${ }^{132} \mathrm{Ba}$ & ${ }^{133 \mathrm{~m}} \mathrm{Ba}$ & 0.961113 & 0.921759 \\
\hline${ }^{55} \mathrm{Mn}$ & ${ }^{56} \mathrm{Mn}$ & 0.768236 & 0.591296 & ${ }^{138} \mathrm{Ba}$ & ${ }^{139} \mathrm{Ba}$ & 0.721393 & 0.434897 \\
\hline${ }^{58} \mathrm{Fe}$ & ${ }^{59} \mathrm{Fe}$ & 0.744577 & 0.553371 & ${ }^{139} \mathrm{La}$ & ${ }^{140} \mathrm{La}$ & 0.824392 & 0.703294 \\
\hline${ }^{59} \mathrm{Co}$ & ${ }^{60} \mathrm{Co}$ & 0.899648 & 0.792867 & ${ }^{140} \mathrm{Ce}$ & ${ }^{141} \mathrm{Ce}$ & 0.696096 & 0.429943 \\
\hline${ }^{64} \mathrm{Ni}$ & ${ }^{65} \mathrm{Ni}$ & 0.603571 & 0.327784 & ${ }^{142} \mathrm{Ce}$ & ${ }^{143} \mathrm{Ce}$ & 0.798767 & 0.600323 \\
\hline${ }^{63} \mathrm{Cu}$ & ${ }^{64} \mathrm{Cu}$ & 0.786528 & 0.594356 & ${ }^{141} \mathrm{Pr}$ & ${ }^{142 \mathrm{~m}} \mathrm{Pr}$ & 0.84513 & 0.710838 \\
\hline${ }^{65} \mathrm{Cu}$ & ${ }^{66} \mathrm{Cu}$ & 0.768558 & 0.578803 & ${ }^{146} \mathrm{Nd}$ & ${ }^{147} \mathrm{Nd}$ & 0.884097 & 0.750436 \\
\hline${ }^{64} \mathrm{Zn}$ & ${ }^{65} \mathrm{Zn}$ & 0.879728 & 0.716396 & ${ }^{148} \mathrm{Nd}$ & ${ }^{149} \mathrm{Nd}$ & 0.956282 & 0.908206 \\
\hline${ }^{68} \mathrm{Zn}$ & ${ }^{69 m} \mathrm{Zn}$ & 0.928832 & 0.842012 & ${ }^{150} \mathrm{Nd}$ & ${ }^{151} \mathrm{Nd}$ & 0.982296 & 0.962764 \\
\hline${ }^{71} \mathrm{Ga}$ & ${ }^{72} \mathrm{Ga}$ & 0.967117 & 0.932900 & ${ }^{152} \mathrm{Sm}$ & ${ }^{153} \mathrm{Sm}$ & 0.995457 & 0.985053 \\
\hline${ }^{75} \mathrm{As}$ & ${ }^{76} \mathrm{As}$ & 0.984389 & 0.968602 & ${ }^{154} \mathrm{Sm}$ & ${ }^{155} \mathrm{Sm}$ & 0.949148 & 0.899154 \\
\hline${ }^{74} \mathrm{Se}$ & ${ }^{75} \mathrm{Se}$ & 0.982325 & 0.966392 & ${ }^{153} \mathrm{Eu}$ & ${ }^{154 \mathrm{~m}} \mathrm{Eu}$ & 1.002410 & 0.972428 \\
\hline${ }^{79} \mathrm{Br}$ & ${ }^{80 \mathrm{~m}} \mathrm{Br}$ & 0.984481 & 0.963835 & ${ }^{158} \mathrm{Gd}$ & ${ }^{159} \mathrm{Gd}$ & 0.993709 & 0.987888 \\
\hline${ }^{81} \mathrm{Br}$ & ${ }^{82 \mathrm{~m}} \mathrm{Br}$ & 0.988802 & 0.976569 & ${ }^{160} \mathrm{Gd}$ & ${ }^{161} \mathrm{Gd}$ & 0.941083 & 0.869589 \\
\hline${ }^{85} \mathrm{Rb}$ & ${ }^{86 m} \mathrm{Rb}$ & 0.985106 & 0.962061 & ${ }^{159} \mathrm{~Tb}$ & ${ }^{160} \mathrm{~Tb}$ & 0.991765 & 0.983428 \\
\hline${ }^{87} \mathrm{Rb}$ & ${ }^{88} \mathrm{Rb}$ & 0.990543 & 0.978106 & ${ }^{164}$ Dy & ${ }^{165 m} \mathrm{Dy}$ & -0.59612 & -0.13894 \\
\hline${ }^{84} \mathrm{Sr}$ & ${ }^{85 \mathrm{~m}} \mathrm{Sr}$ & 0.984748 & 0.963917 & ${ }^{165} \mathrm{Ho}$ & ${ }^{166} \mathrm{Ho}$ & 0.989663 & 0.976313 \\
\hline${ }^{86} \mathrm{Sr}$ & ${ }^{87 \mathrm{~m}} \mathrm{Sr}$ & 0.945262 & 0.87112 & ${ }^{170} \mathrm{Er}$ & ${ }^{171} \mathrm{Er}$ & 0.950799 & 0.903065 \\
\hline${ }^{89} \mathrm{Y}$ & ${ }^{90 \mathrm{~m}} \mathrm{Y}$ & 0.963615 & 0.891243 & ${ }^{169} \mathrm{Tm}$ & ${ }^{170} \mathrm{Tm}$ & 1.004700 & 0.991756 \\
\hline${ }^{94} \mathrm{Zr}$ & ${ }^{95} \mathrm{Zr}$ & 0.957566 & 0.87700 & ${ }^{174} \mathrm{Yb}$ & ${ }^{175} \mathrm{Yb}$ & 0.357880 & 0.221067 \\
\hline${ }^{96} \mathrm{Zr}$ & ${ }^{97} \mathrm{Zr}$ & 0.999115 & 0.997943 & ${ }^{176} \mathrm{Yb}$ & ${ }^{177} \mathrm{Yb}$ & 0.908488 & 0.809688 \\
\hline${ }^{93} \mathrm{Nb}$ & ${ }^{94 \mathrm{~m}} \mathrm{Nb}$ & 0.969700 & 0.928380 & ${ }^{175} \mathrm{Lu}$ & ${ }^{176 \mathrm{~m}} \mathrm{Lu}$ & 0.996032 & 0.991774 \\
\hline${ }^{98} \mathrm{Mo}$ & ${ }^{99} \mathrm{Mo}$ & 0.995883 & 0.990853 & ${ }^{174} \mathrm{Hf}$ & ${ }^{175} \mathrm{Hf}$ & 0.759887 & 0.609407 \\
\hline${ }^{100} \mathrm{Mo}$ & ${ }^{101} \mathrm{Mo}$ & 0.988295 & 0.970848 & ${ }^{179} \mathrm{Hf}$ & ${ }^{180 \mathrm{~m}} \mathrm{Hf}$ & 0.990364 & 0.980132 \\
\hline${ }^{96} \mathrm{Ru}$ & ${ }^{97} \mathrm{Ru}$ & 0.991702 & 0.978811 & ${ }^{180} \mathrm{Hf}$ & ${ }^{181} \mathrm{Hf}$ & 0.913130 & 0.837096 \\
\hline${ }^{102} \mathrm{Ru}$ & ${ }^{103} \mathrm{Ru}$ & 0.938892 & 0.877634 & ${ }^{181} \mathrm{Ta}$ & ${ }^{182 \mathrm{~m}} \mathrm{Ta}$ & 0.997216 & 0.992780 \\
\hline${ }^{104} \mathrm{Ru}$ & ${ }^{105} \mathrm{Ru}$ & 0.982706 & 0.958954 & ${ }^{186} \mathrm{~W}$ & ${ }^{187} \mathrm{~W}$ & 0.988597 & 0.977570 \\
\hline${ }^{103} \mathrm{Rh}$ & ${ }^{104 \mathrm{~m}} \mathrm{Rh}$ & 1.29702 & 1.11028 & ${ }^{185} \mathrm{Re}$ & ${ }^{186} \mathrm{Re}$ & 1.014020 & 0.998171 \\
\hline${ }^{108} \mathrm{Pd}$ & ${ }^{109 \mathrm{~m}} \mathrm{Pd}$ & 0.993450 & 0.987460 & ${ }^{187} \mathrm{Re}$ & ${ }^{188 m} \mathrm{Re}$ & 0.958039 & 0.921987 \\
\hline${ }^{110} \mathrm{Pd}$ & ${ }^{111 \mathrm{~m}} \mathrm{Pd}$ & 0.989017 & 0.971347 & ${ }^{190} \mathrm{Os}$ & ${ }^{191 \mathrm{~m}} \mathrm{Os}$ & 0.891403 & 0.800890 \\
\hline${ }^{107} \mathrm{Ag}$ & ${ }^{108} \mathrm{Ag}$ & 0.934276 & 0.880183 & ${ }^{192} \mathrm{Os}$ & ${ }^{193} \mathrm{Os}$ & 0.908020 & 0.831151 \\
\hline${ }^{109} \mathrm{Ag}$ & ${ }^{110 \mathrm{~m}} \mathrm{Ag}$ & 1.00012 & 0.990589 & ${ }^{193} \mathrm{Ir}$ & ${ }^{194} \mathrm{Ir}$ & 1.049670 & 1.015320 \\
\hline${ }^{114} \mathrm{Cd}$ & ${ }^{115} \mathrm{Cd}$ & 0.994496 & 0.988007 & ${ }^{198} \mathrm{Pt}$ & ${ }^{199 m} \mathrm{Pt}$ & 0.987525 & 0.974821 \\
\hline${ }^{113} \mathrm{In}$ & ${ }^{114 m} \mathrm{In}$ & 0.999628 & 0.993641 & ${ }^{197} \mathrm{Au}$ & ${ }^{198} \mathrm{Au}$ & 1.001300 & 0.990335 \\
\hline${ }^{115} \mathrm{In}$ & ${ }^{116 \mathrm{~m}} \mathrm{In}$ & 1.07891 & 1.03788 & ${ }^{196} \mathrm{Hg}$ & ${ }^{197 \mathrm{~m}} \mathrm{Hg}$ & 0.493779 & -0.32989 \\
\hline${ }^{112} \mathrm{Sn}$ & ${ }^{113 \mathrm{~m}} \mathrm{Sn}$ & 0.995628 & 0.991087 & ${ }^{238} \mathrm{U}$ & ${ }^{239} \mathrm{U}$ & 1.0004 & 0.99725 \\
\hline
\end{tabular}


Table 2. Ratio of $Q_{0}(\alpha)$ calculated by Equations (4) and (5) to Equation (3) of some nuclide in reaction ( $n$, $\left.\not\right)$ using in NAA.

\begin{tabular}{ccccc}
\hline Nuclide & Formed nuclide & $Q_{0}$ & Ratio of Equation (5)/Equation (3) & Ratio of Equation (4)/Equation (3) \\
\hline${ }^{164} \mathrm{Dy}$ & ${ }^{165} \mathrm{Dy}$ & 0.25 & 0.98 & 2.15 \\
${ }^{45} \mathrm{Sc}$ & ${ }^{46} \mathrm{Sc}$ & 0.43 & 1.01 & 1.934 \\
${ }^{50} \mathrm{Cr}$ & ${ }^{51} \mathrm{Cr}$ & 0.53 & 1.042 & 1.708 \\
${ }^{51 \mathrm{~V}}$ & ${ }^{52 \mathrm{~V}}$ & 0.55 & 1.052 & 1.665 \\
${ }^{23} \mathrm{Na}$ & ${ }^{24} \mathrm{Na}$ & 0.59 & 1.037 & 1.6 \\
${ }^{26} \mathrm{Mg}$ & ${ }^{27} \mathrm{Mg}$ & 0.64 & 1.05 & 1.59 \\
${ }^{50} \mathrm{Ti}$ & ${ }^{51} \mathrm{Ti}$ & 0.67 & 1,049 & 1.534 \\
${ }^{37} \mathrm{Cl}$ & ${ }^{38} \mathrm{Cl}$ & 0.69 & 1.049 & 1.508 \\
${ }^{27} \mathrm{Al}$ & ${ }^{28} \mathrm{Al}$ & 0.71 & 1.012 & 1.48 \\
${ }^{59} \mathrm{Co}$ & ${ }^{60} \mathrm{Co}$ & 1.99 & 1.001 & 1.064 \\
${ }^{186} \mathrm{~W}$ & ${ }^{187} \mathrm{~W}$ & 13.8 & 1.0 & 1.008 \\
${ }^{98} \mathrm{Mo}$ & ${ }^{99} \mathrm{Mo}$ & 53.8 & 1.0 & 1.002 \\
${ }^{96} \mathrm{Zr}$ & ${ }^{97} \mathrm{Zr}$ & 248 & 1.0
\end{tabular}

Table 3. The results calculated $Q_{0 i}(\alpha)$ from three expression Equations (3)-(5) with $\alpha$ in interval $[-0.2,0.2]$ for ${ }^{45} \mathrm{Sc}(n$, $\gamma^{46}$ Sc.

\begin{tabular}{cccccccc}
\hline Value of $\alpha$ & $\begin{array}{c}Q_{0 i}(\alpha) \text { from } \\
\text { Equation (3) }\end{array}$ & $\begin{array}{c}Q_{0 i}(\alpha) \text { from } \\
\text { Equation (5) }\end{array}$ & $\begin{array}{c}Q_{0 i}(\alpha) \text { from } \\
\text { Equation (4) }\end{array}$ & Value of $\alpha$ & $\begin{array}{c}Q_{0 i}(\alpha) \text { from } \\
\text { Equation (3) }\end{array}$ & $\begin{array}{c}Q_{0 i}(\alpha) \text { from } \\
\text { Equation }(5)\end{array}$ & $\begin{array}{c}Q_{0 i}(\alpha) \text { from } \\
\text { Equation }(4)\end{array}$ \\
\hline$-0,20$ & 0.7072 & 0.6850 & 2.429 & 0.02 & 0.4263 & 0.4287 & 0.371 \\
-0.18 & 0.6629 & 0.6554 & 2.048 & 0.04 & 0.4139 & 0.4178 & 0.313 \\
-0.16 & 0.6242 & 0.6270 & 1.726 & 0.06 & 0.4026 & 0.4071 & 0.264 \\
-0.14 & 0.5905 & 0.5998 & 1.455 & 0.08 & 0.3923 & 0.3967 & 0.222 \\
-0.12 & 0.5607 & 0.5738 & 1.227 & 0.10 & 0.3828 & 0.3865 & 0.187 \\
-0.10 & 0.5345 & 0.5490 & 1.034 & 0.12 & 0.3741 & 0.3767 & 0.158 \\
-0.08 & 0.5112 & 0.5252 & 0.872 & 0.14 & 0.3661 & 0.3671 & 0.133 \\
-0.06 & 0.4905 & 0.5025 & 0.7346 & 0.16 & 0.3587 & 0.3577 & 0.112 \\
-0.04 & 0.4718 & 0.4807 & 0.619 & 0.18 & 0.3518 & 0.3486 & 0.095 \\
-0.02 & 0.4551 & 0.4599 & 0.522 & 0.20 & 0.3455 & 0.3396 & 0.080 \\
\hline
\end{tabular}

Notice: Equation (3): true expression; Equation (5): expression in this work; Equation (4): expression in paper [6] of J. Op De Beek.

From Table 1, it shows that coefficients $a_{i}$ of nuclides having $Q_{0 i}>1$ are close to unity, but $a_{i}$ of the nuclides having $Q_{0 i}<1$ differs more than unity. Therefore, the approximation of Equation (4) in paper [6] is only acceptable for the nuclides having $Q_{0 i}>1$, but for the nuclides having $Q_{0 i}<1$, it is not reliable.

In this work, we use the approximation expression; Equation (5), to evaluate influence of the uncertainties of $\alpha, f$ and $\bar{E}_{r i}$ on the final element concentration in $k_{0}$-method in the channels; 7 - 1 , neutron trap of Dalat reactor (Vietnam) and channel 17 of THETIS reactor (Belgium) for the nuclides; ${ }^{45} \mathrm{Sc},{ }^{59} \mathrm{Co},{ }^{94} \mathrm{Zr},{ }^{186} \mathrm{~W},{ }^{197} \mathrm{Au}$, ${ }^{98} \mathrm{Mo},{ }^{96} \mathrm{Zr}$. We choose these nuclides, because they differ considerably in $Q_{0 i}$ and $\bar{E}_{r i}$ values. The numerical data of concerning isotopes and irradiation channels used in this work are summarized in Tables $\mathbf{4}$ and 5.

\section{Results and Discussion}

The absolute uncertainty in $\rho$ can be calculated from the uncertainties of the variables (denoted $x_{j}$ ) which determine $\rho$ in Equation (1):

$$
s_{\rho}=\sqrt{\sum_{j} s_{x_{j}}^{2}\left(\frac{\partial \rho}{\partial x_{j}}\right)^{2}}
$$

where $\partial \alpha / \partial x_{j}$ are the corresponding partial derivatives.

According to the customary error propagation theory, 
Table 4. Characteristics of isotopes used in the calculations of this work.

\begin{tabular}{ccc}
\hline Nuclide & $Q_{0}=I_{0} / \sigma_{0}$ & $\bar{E}_{\mathrm{r}}(\mathrm{eV})$ \\
\hline${ }^{45} \mathrm{Sc}$ & 0.44 & 5130 \\
${ }^{59} \mathrm{Co}$ & 1.993 & 136 \\
${ }^{94} \mathrm{Zr}$ & 5.05 & 6260 \\
${ }^{186} \mathrm{~W}$ & 13.7 & 20.5 \\
${ }^{197} \mathrm{Au}$ & 15.7 & 5.65 \\
${ }^{98} \mathrm{Mo}$ & 53.1 & 241 \\
${ }^{96} \mathrm{Zr}$ & 248 & 338 \\
\hline
\end{tabular}

Table 5. Characteristics of irradiation channels considered: channles 17 of Thetis reactor, Belgium [9], 7 - 1 channel and neutron trap of Dalat reactor, Vietnam.

\begin{tabular}{ccc}
\hline Channel & $\alpha$ & $f$ \\
\hline Channel 7 - 1 (Dalat reactor) & $-0.044 \pm 0.004$ & $14.2 \pm 0.5$ \\
Neutron trap (Dalat reactor) & $-0.031 \pm 0.004$ & $33.0 \pm 0.5$ \\
Channel 17 (Thetis reactor) & -0.028 & 15.0 \\
\hline
\end{tabular}

the error propagation functions can be written as:

$$
Z_{\rho}\left(x_{j}\right)=\left|\left(\frac{\partial \rho}{\rho}\right) /\left(\frac{\partial x_{j}}{x_{j}}\right)\right|=\left|\frac{\partial \rho}{\partial x_{j}} \frac{x_{j}}{\rho}\right|
$$

and relative error is:

$$
s_{\rho}\left(x_{j}\right)=Z_{\rho}\left(x_{j}\right) \frac{\Delta x_{j}}{x_{j}}
$$

\subsection{Influence of Uncertainty of $\bar{E}_{r i}$ on NAA Results}

From Equation (8), the uncertainty of the concentration $(\rho)$ in $k_{0}$-method due to the uncertainties of the effective resonace energies can be written by:

$$
\left.\frac{\Delta \rho}{\rho}\right|_{\bar{E}_{r i}}=Z_{\rho}\left(\bar{E}_{r i}\right) \frac{\Delta \bar{E}_{r i}}{\bar{E}_{r i}}
$$

Using Equation (7) for the effective resonance energy of the nuclide $i$, we obtain:

$$
Z_{\rho}\left(\bar{E}_{r i}\right)=\left|\alpha\left(\frac{a_{i} Q_{0 i}}{Q_{0 i}+f\left(\bar{E}_{r i}\right)^{a_{i} \alpha}}\right)\right|
$$

The values of calculated $Z_{\rho}\left(\bar{E}_{r i}\right)$ for chosen nuclides are presented in Table 6. The effect of the effective resonance energy on NAA result include the uncertainties of the effective resonance energies of analytical and comparator nuclides. In this case, Au used as comparator with $\bar{E}_{A u}$ of $5.65 \mathrm{eV}$ and uncertainty of $7.1 \%$ from paper [5], the contribution of the uncertainty of $\bar{E}_{A u}$ to the error of NAA result in channels $7-1$, neutron trap of Dalat reactor and channel 17 of THETIS reactor is $0.17 \%, 0.077 \%$ and $0.13 \%$, respectively. Clearly, the effect of the uncertainty of the effective resonance energy of $\mathrm{Au}$ is negligible and can be overlooked in the evaluation.

The analysis for 94 nuclides used in NAA showed that the uncertainties of their effective resonace energy are from 0 to $20 \%$, except ${ }^{75}$ As (34\%) [4]. In this measure, we are able to realize that the effect of them on NAA result is also negligible. For example, ${ }^{45} \mathrm{Sc}\left(\bar{E}_{r}=5130\right.$ $\left.\mathrm{eV}, \Delta \bar{E}_{r}=17 \%\right)$ and ${ }^{95} \mathrm{Zr}\left(\bar{E}_{r}=338 \mathrm{eV}, \Delta \bar{E}_{r}=2.1 \%\right)$, the contribution of the uncertainty of the effective resonance energy to the error of NAA result in three above channels is less than $0.01 \%$ for ${ }^{45} \mathrm{Sc}$ and $0.1 \%$ for ${ }^{95} \mathrm{Zr}$.

In epicadmium neutron activation analysis (ENAA), the f-term in Equation (10) should be omitted. The error propagation function of $\bar{E}_{r i}$ can be written:

$$
Z_{\rho}\left(\bar{E}_{r i}\right)=\left|\alpha a_{i}\right|
$$

The calculated results of $Z_{\rho}\left(\bar{E}_{r i}\right)$ for the nuclides; ${ }^{45} \mathrm{Sc},{ }^{59} \mathrm{Co},{ }^{94} \mathrm{Zr},{ }^{186} \mathrm{~W},{ }^{197} \mathrm{Au},{ }^{98} \mathrm{Mo},{ }^{96} \mathrm{Zr}$ in ENAA are carried in Table 7. In this case, the error propagation function is higher than in the one of irradiation without cadmium. Generaly speaking, $a_{i}<1$ and if $\alpha \ll 1$, the contribution of $\Delta \bar{E}_{r i}$ to the error of NAA result for almost analytical nuclides is less than $1 \%$ and can be omitted in the calculation.

\subsection{Influence of Uncertainty of $\alpha$ on NAA Results}

Also from Equation (8), the uncertainty of $\rho$ due to the uncertainty of $\alpha$ can be written:

$$
\left.\frac{\Delta \rho}{\rho}\right|_{\alpha}=Z_{\rho}(\alpha) \frac{\Delta \alpha}{\alpha}
$$

and error propagation function of $\alpha$.

$$
Z_{\rho}(\alpha)=\left|-\alpha\left(\frac{a_{i}^{*} Q_{0 i}^{*} \ln \left(\bar{E}_{r i}^{*}\right)}{Q_{0 i}^{*}+f\left(\bar{E}_{r i}^{*}\right)^{a_{i}^{*} \alpha}}-\frac{a_{i} Q_{0 i} \ln \left(\bar{E}_{r i}\right)}{Q_{0 i}+f\left(\bar{E}_{r i}\right)^{a_{i} \alpha}}\right)\right|
$$

The values of the error propagation function of $\alpha$ in the channels; 7 - 1 and neutron trap of Dalat reactor (Vietnam) and channel 17 of THETIS reactor (Belgium) for the nuclides; ${ }^{45} \mathrm{Sc},{ }^{59} \mathrm{Co},{ }^{94} \mathrm{Zr},{ }^{186} \mathrm{~W},{ }^{197} \mathrm{Au},{ }^{98} \mathrm{Mo},{ }^{96} \mathrm{Zr}$ were shown in Table 8. From Table 8, for the nuclides having $Q_{0}<Q_{0 A u}$ in three these channels, the contribution of the uncertainty of $\alpha$ to the error of NAA result is not significant, about less than $1 \%$. But for nuclides having $Q_{0} \gg Q_{0 A u}$, this effect is noticeable. For instance, in channel 7 - 1 of Dalat reactor $(\alpha=-0.044, \Delta \alpha=12 \%$ 
Table 6. Calculation results of $Z_{\rho}\left(\bar{E}_{r i}\right)$ for chosen nuclides.

\begin{tabular}{cccc}
\hline Nuclide & $\begin{array}{c}7 \text { - 1 channel } \\
\text { (Dalat reactor) }\end{array}$ & $\begin{array}{c}\text { Neutron trap } \\
\text { (Dalat reactor) }\end{array}$ & $\begin{array}{c}\text { Channel 17 } \\
\text { (THETIS reactor) }\end{array}$ \\
\hline${ }^{45} \mathrm{Sc}$ & 0.000316 & 0.000102 & 0.000185 \\
${ }^{59} \mathrm{Co}$ & 0.005765 & 0.001939 & 0.00329 \\
${ }^{94} \mathrm{Zr}$ & 0.01430 & 0.005304 & 0.008004 \\
${ }^{185} \mathrm{~W}$ & 0.02278 & 0.01025 & 0.01379 \\
${ }^{197} \mathrm{Au}$ & 0.02396 & 0.01106 & 0.01467 \\
${ }^{98} \mathrm{Mo}$ & 0.03620 & 0.02163 & 0.02244 \\
${ }^{96} \mathrm{Zr}$ & 0.04601 & 0.03065 & 0.02671 \\
\hline
\end{tabular}

Table 7. Calculated results of $Z_{\rho}\left(\bar{E}_{r i}\right)$ for the nuclides in ENAA.

\begin{tabular}{cccc}
\hline Nuclide & $\begin{array}{c}7-1 \text { channel } \\
\text { (Dalat reactor) }\end{array}$ & $\begin{array}{c}\text { Neutron trap } \\
\text { (Dalat reactor) }\end{array}$ & $\begin{array}{c}\text { Channel 17 } \\
\text { (THETIS reactor) }\end{array}$ \\
\hline${ }^{45} \mathrm{Sc}$ & 0.00991 & 0.00743 & 0.00631 \\
${ }^{59} \mathrm{Co}$ & 0.03958 & 0.02969 & 0.02519 \\
${ }^{94} \mathrm{Zr}$ & 0.04213 & 0.03160 & 0.02681 \\
${ }^{185} \mathrm{~W}$ & 0.04350 & 0.03262 & 0.02768 \\
${ }^{197} \mathrm{Au}$ & 0.04406 & 0.03304 & 0.02803 \\
${ }^{98} \mathrm{Mo}$ & 0.04382 & 0.03286 & 0.02788 \\
${ }^{96} \mathrm{Zr}$ & 0.04396 & 0.03329 & 0.02797 \\
\hline
\end{tabular}

Table 8. Calculation results of $Z_{\rho}(\alpha)$ for chosen nuclides.

\begin{tabular}{cccc}
\hline Nuclide & $\begin{array}{c}7-1 \text { channel } \\
\text { (Dalat reactor) }\end{array}$ & $\begin{array}{c}\text { Neutron trap } \\
\text { (Dalat reactor) }\end{array}$ & $\begin{array}{c}\text { Channel 17 } \\
\text { (THETIS reactor) }\end{array}$ \\
\hline${ }^{45} \mathrm{Sc}$ & 0.03571 & 0.01684 & 0.02241 \\
${ }^{59} \mathrm{Co}$ & 0.01755 & 0.01022 & 0.01055 \\
${ }^{94} \mathrm{Zr}$ & 0.03379 & 0.01083 & 0.02489 \\
${ }^{185} \mathrm{~W}$ & 0.02154 & 0.00916 & 0.01390 \\
${ }^{197} \mathrm{Au}$ & 0.000 & 0.000 & 0.000 \\
${ }^{98} \mathrm{Mo}$ & 0.11340 & 0.07016 & 0.07294 \\
${ }^{96} \mathrm{Zr}$ & 0.19924 & 0.14750 & 0.12751 \\
\hline
\end{tabular}

$[7,8]$ ), the contribution of the uncertainty of $\alpha$ on the error of result of ${ }^{45} \mathrm{Sc}\left(Q_{0}=0.44\right)$ is $0.42 \%$, but for ${ }^{99} \mathrm{Mo}$ and ${ }^{96} \mathrm{Zr}$ is $1.36 \%$ and $2.4 \%$, respectively. As a comment, for RNAA using ${ }^{197} \mathrm{Au}$ comparator, the systematic effect for $\alpha$ value up to 0.1 is practically negligible for all nuclides with a low enough $Q_{0}$ value (e.g. ${ }^{45} \mathrm{Sc},{ }^{59} \mathrm{Co},{ }^{58} \mathrm{Fe}$, ect.). On the other hand, for nuclides with a relatively large $Q_{0}$ value, a correction for the $\alpha$ effect becomes really necessary. To reduce the $\alpha$ effect, it is either to develop more accurate and precise techniques for $\alpha$ determination or to choose the irradiation channels with the $\alpha$ value low enough.

In the case of the epicadmium neutron activation, Equation (13) can be changed into:

$$
Z_{\rho}(\alpha)=\left|-\alpha\left(a_{i}^{*} \ln \left(\bar{E}_{r i}^{*}\right)-a_{i} \ln \left(\bar{E}_{r i}\right)\right)\right|
$$

The values of the error propagation of $\alpha$ in this case were carried in Table 9. In this case, it clearly shows the inaccuracy of the approximation expression in [6] (Equation (4) in this report). Really, according to Equation (4), the error propagation function of $\alpha$ in the irradiation with cadmium can be written:

$$
Z_{\rho}(\alpha)=\left|-\alpha\left(\ln \left(\bar{E}_{r i}^{*}\right)-\ln \left(\bar{E}_{r i}\right)\right)\right|
$$

Equation (15) is different to Equation (14) by the correctional coefficients $a_{i}$. However, the value of the error propagation function in channel 7 - 1 of Dalat reactor, for ${ }^{45} \mathrm{Sc}$ is 0.0083 from Equation (14) and 0.2997 from Equation (15). If the uncertainty of $\alpha$ in experiment is $100 \%$, the contribution of uncertainty of $\alpha$ on NAA result is $0.83 \%$ and $29.97 \%$, respectively. It differs by a factor of 30 (!). Similarly, in channel 17 of Thetis reactor, the error propagation function for ${ }^{45} \mathrm{Sc}$ is 0.0053 and 0.1907 . The difference is huge. This comment is also correct for nuclides having $Q_{0}<1$. It once more confirms that the approximation expression in paper [6] is not good for nuclides having $Q_{0}<1$.

From Equation (13) or Equation (14), we easily estimate the influence of $\alpha$ on NAA results, if we know uncertainty of $\alpha$ in the irradiation channel. However, for ENAA (epicadmium neutron activation analysis) the situation is much more dramatic, especially for nuclides with low $Q_{0}$ value.

\subsection{Influence of Uncertainty of $\boldsymbol{f}$ on NAA Results}

The error propagation function $Z_{\rho}(f)$ can be written:

$$
Z_{\rho}(f)=\left|-f \frac{Q_{0 i}^{*}\left(\bar{E}_{r i}\right)^{a_{i} \alpha}-Q_{0 i}\left(\bar{E}_{r i}^{*}\right)^{a_{i}^{*} \alpha}}{\left(Q_{0 i}^{*}+f\left(\bar{E}_{r i}^{*}\right)^{a_{i}^{*} \alpha}\right)\left(Q_{0 i}+f\left(\bar{E}_{r i}\right)^{a_{i} \alpha}\right)}\right|
$$

The values of the error propagation function of $\mathrm{f}$ in the channels; 7 - 1 and neutron trap of Dalat reactor and channel 17 of THETIS reactor for the nuclides; ${ }^{45} \mathrm{Sc}$, ${ }^{59} \mathrm{Co},{ }^{94} \mathrm{Zr},{ }^{186} \mathrm{~W},{ }^{197} \mathrm{Au},{ }^{98} \mathrm{Mo},{ }^{96} \mathrm{Zr}$ were carried in Table 9. The uncertainty of $f$ contributes on the error of NAA results is:

$$
\frac{\Delta \rho}{\rho}=Z_{\rho}(f) \frac{\Delta f}{f}
$$

Generally seeing, the uncertainty of $f$ in experiment is about less than 4\%, therefore, from Table 10, the contribution of the uncertainty of $f$ on the error of NAA result 
Table 9. Calculation results of $Z_{\rho}(\alpha)$ for the nuclides in ENAA.

\begin{tabular}{cccc}
\hline Nuclide & $\begin{array}{c}7-1 \text { channel } \\
\text { (Dalat reactor) }\end{array}$ & $\begin{array}{c}\text { Neutron trap } \\
\text { (Dalat reactor) }\end{array}$ & $\begin{array}{c}\text { Channel 17 } \\
\text { (THETIS reactor) }\end{array}$ \\
\hline${ }^{45} \mathrm{Sc}$ & 0.00835 & 0.00626 & 0.00531 \\
${ }^{59} \mathrm{Co}$ & 0.11817 & 0.08863 & 0.07520 \\
${ }^{94} \mathrm{Zr}$ & 0.2920 & 0.2190 & 0.18584 \\
${ }^{186} \mathrm{~W}$ & 0.05509 & 0.04132 & 0.03506 \\
${ }^{197} \mathrm{Au}$ & 0.000 & 0.000 & 0.000 \\
${ }^{98} \mathrm{Mo}$ & 0.1640 & 0.1230 & 0.10439 \\
${ }^{96} \mathrm{Zr}$ & 0.17969 & 0.13477 & 0.11435 \\
\hline
\end{tabular}

Table 10. Calculation results of $Z_{\rho}(f)$ for chosen nuclides.

\begin{tabular}{cccc}
\hline Nuclide & $\begin{array}{c}\text { Channel 7-1 } \\
\text { (Dalat reactor) }\end{array}$ & $\begin{array}{c}\text { Neutron trap } \\
\text { (Dalat reactor) }\end{array}$ & $\begin{array}{c}\text { Channel 17 } \\
\text { (THETIS reactor) }\end{array}$ \\
\hline${ }^{45} \mathrm{Sc}$ & 0.512 & 0.321 & 0.494 \\
${ }^{59} \mathrm{Co}$ & 0.398 & 0.2697 & 0.393 \\
${ }^{94} \mathrm{Zr}$ & 0.204 & 0.167 & 0.225 \\
${ }^{185} \mathrm{~W}$ & 0.0202 & 0.0208 & 0.0252 \\
${ }^{197} \mathrm{Au}$ & 0.0 & 0.0 & 0.0 \\
${ }^{98} \mathrm{Mo}$ & 0.282 & 0.323 & 0.281 \\
${ }^{96} \mathrm{Zr}$ & 0.413 & 0.566 & 0.428 \\
\hline
\end{tabular}

is about less than $2 \%$.

\subsection{Collective Influence of Uncertainties of $\alpha$, $\bar{E}_{r i}$ and $f$ on NAA Results}

In view of the above, we can estimate the influence of the uncertainties of $\alpha, \bar{E}_{r i}$ and $f$ on final NAA results. The contribution of these parameters on the errors of the analysis results is written as:

$$
\left.\frac{\Delta \rho}{\rho}\right|_{\alpha, \overline{E_{r}, \alpha}}=\sqrt{\left(\left.\frac{\Delta \rho}{\rho}\right|_{\alpha}\right)^{2}+\left(\left.\frac{\Delta \rho}{\rho}\right|_{\bar{E}_{r}}\right)^{2}+\left(\left.\frac{\Delta \rho}{\rho}\right|_{f}\right)^{2}}
$$

However, as discussion above, the $\bar{E}_{r}$ effect is negligible and can be omitted in Equation (18). Thus, the contribution on error of NAA results in this case is primarily due to the uncertainties of $\alpha$ and $f$. Finally, as well as estimation above, this overall contribution of $\alpha$ and $f$ is about $2 \%$ on the error of NAA results. It was also confirmed by actual analysis.

\section{Conclusion}

For $\alpha$ in the irradiation position relatively small $(\alpha \ll 1)$, Equation (5) is a good approximation to estimate influence of the neutron flux characteristics on NAA result using the $k_{0}$ standardization method. From this approxi- mative expression, the error propagation functions of the parameters were presented. They can be used for the estimation of the errors on NAA due to the uncertainty of the neutron flux characteristic parameters at the irradiation position. From the results of this report, it was also confirmed that the approximation in paper [6] is only acceptable for the nuclides having $Q_{0 i}>1$, but not for the nuclides having $Q_{0 i}<1$.

\section{REFERENCES}

[1] A. Simonits, F. De Corte and J. Hoste, "Single-Comparator Methods in Reactor Neutron Activation Analysis," Journal of Radioanalytical and Nuclear Chemistry, Vol. 24, No. 1, 1975, pp. 31-46. doi: $10.1007 / \mathrm{BF} 02514380$

[2] A. Simonits, L. Moens, F. De Corte, A. De Wispelaere, A. Elek and J. Hoste, " $k_{0}$-Measurements and Related Nuclear Data Comilation for $(n, \gamma)$ Reactor Neutron Activation Analysis," Journal of Radioanalytical and Nuclear Chemistry, Vol. 60, No. 2, 1980, pp. 461-516. doi:10.1007/BF02518906

[3] L. Moens, F. De Corte, A. De Wispelaere, J. Hoste, A. Simonits, A. Elek and J. Szabo, " $k_{0}$-Measurements and Related Nuclear Data Comilation for $(n, \gamma)$ Reactor Neutron Activation Analysis," Journal of Radioanalytical and Nuclear Chemistry, Vol. 82, No. 2, 1984, pp. 385-452. doi:10.1007/BF02037061

[4] F. De Corte, A. Simonits, F. De Wispelaere and J. Hoste, "A Compilation of $k_{0}$-Factors and Related Nuclear Data for 94 Radionuclides of Interest in NAA," INW/KFKI Interim Report, 1986.

[5] F. De Corte, A. Simonits, A. De Wispelaere and J. Hoste, "Accuracy and Applicability of the $k_{0}$-Standardization Method," Journal of Radioanalytical and Nuclear Chemistry, Vol. 113, No. 1, 1987, pp. 145-161. doi:10.1007/BF02036056

[6] J. Op De Beek, "Critical Evaluation of the Effective Resonance Energy Concept and the Epithemal Neutron Spectrum Shape-factor $\alpha$ for Reactor NAA Purposes," Journal of Radioanalytical and Nuclear Chemistry, Vol. 89, No. 1, 1985, pp. 169-190.

[7] T. V. Hung, "Determination of $\alpha$ Factor of Epithemal Neutron Flux in Dalat Reactor, Vietnam, Based on Neutron Spectrum Calculated Using MCNP Code," Journal of Radioanalytical and Nuclear Chemistry, Vol. 283, No. 2, 2010, pp. 707-711. doi:10.1007/s10967-010-0457-0

[8] T. V. Hung, "Modified Method of $\alpha$ Determination in the $1 / E^{1+\alpha}$ Epithermal Neutron Spectrum of Reactor," Journal of Radioanalytical and Nuclear Chemistry, Vol. 285, No. 2, 2010, pp. 331-336. doi:10.1007/s10967-010-0549-x

[9] F. De Corte, L. Moens, A. Simonits, K. Sordo-el Hammami, A. De Wispelaere and J. Hoste, "The Effect of the Epithermal Neutron Flux Distribution on the Accuracy of Absolue and Comparator Standardization Method in $(\mathrm{n}, \gamma)$ Activation Analysis," Journal of Radioanalytical and $\mathrm{Nu}$ clear Chemistry, Vol. 72, No. 1-2, 1982, pp. 275-286. 